\title{
Milk Production, Somatic Cell Count, Percentages Milk Fat and Milk Protein Measured in Lactating Dairy Goats Fed a Nutritional Supplement
}

\author{
Rowson $\mathrm{A}^{* 1}$, Armstrong $\mathrm{S}^{1}$, Boyle $\mathrm{T}^{1}$, Puntenney $\mathrm{S}^{1}$, Ely $\mathrm{L}^{2}$ and McLean $\mathrm{D}^{1}$ \\ ${ }^{1}$ Phibro Animal Health Corporation, Quincy, IL, USA \\ ${ }^{2}$ Department of Animal and Dairy Science, University of Georgia, Athens, GA, USA
}

*Corresponding author: Rowson A, Phibro Animal Health Corporation, Quincy, IL, USA, Tel: 563-4514381, E-mail: Angie.Rowson@pahc.com

Citation: Rowson A, Armstrong S, Boyle T, Puntenney S, Ely L, et al. (2016) Milk Production, Somatic Cell Count, Percentages Milk Fat and Milk Protein Measured in Lactating Dairy Goats Fed a Nutritional Supplement. J Vet Sci Anim Husb 4(3): 301

Received Date: February 16, 2016 Accepted Date: November 21, 2016 Published Date: November 23, 2016

\begin{abstract}
Two replicate studies were conducted on a commercial goat dairy. The objective was to determine the effects of dietary supplementation with OmniGen-AF, a nutritional supplement that supports immune function in ruminants, on milk production, somatic cell count (SCC), percentages milk fat (\%MF) and milk protein (\%MP) in lactating dairy goats. In the first replicate, thirty-five, two-year old does were randomly assigned to either: 1) Basal diet (Control; $\mathrm{n}=18$ ), or 2) Basal diet + OmniGen-AF (OG; $\mathrm{n}=17)$. In the second replicate, forty-four, two-year old does were randomly assigned to the same dietary treatments with 22 does per treatment. Dairy Herd Improvement Association milk testing (DHIA) was performed approximately every 28 days during lactation resulting in a total of nine tests per replicate. Milk production, \%MF, \%MP, fat corrected milk (FCM), energy corrected milk (ECM), SCC and linear score somatic cell count (L.S. SCC) data were collected at each test. Combining the results from the replicate studies indicated the overall mean SCC $(P=0.089)$ tended to be lower for OG does compared to controls, with the largest difference occurring at DHIA milk test 9, where OG supplementation reduced SCC by $1,163,300 \mathrm{ml}^{-1}(P=0.038)$. L.S.SCC was also lower $(P=0.008)$ for OG does at milk test 9 compared to controls (6.19 and 7.23, respectively) Mean \%MF and \%MP were greater for OG does than for controls ( $P=0.010$ and $P=0.049$, respectively) FCM was greater $(P=0.046)$ and ECM tended to be greater in OG does $(P=0.07)$ compared to control does. The improvements in milk production and quality observed suggest enhanced mammary health in dairy goats supplemented with OmniGen-AF.
\end{abstract}

Keywords: Dairy goat; Milk; Somatic cell count; DHIA; OmniGen-AF

List of Abbreviations: \%MF: Percentage milk fat; \%MP: Percentage milk protein; FCM: Fat Corrected Milk; ECM: Energy Corrected Milk; SCC: Somatic Cell Count; L.S.SCC: Linear Score Somatic Cell Count; DHIA: Dairy Herd Improvement Association; IMI: Intramammary Infection; CNS: Coagulase-Negative Staphylococci; CP: Crude Protein; Ca: Calcium; Cu: Copper; Se: Selenium; OG: OmniGen-AF; kg: Kilogram; DIM: Days in Milk; S.E.: Standard Error; ppm: Parts per Million; h: Head; d: Day; g: Gram

\section{Introduction}

There are approximately 375,000 dairy goats and kids in the United States with Wisconsin, California and Iowa having the largest numbers, respectively [1]. Dairy goat milk and cheese are considered specialty foods in high demand by modern day consumers, and product sales have grown steadily as consumers have become more aware of the potential health benefits of goat milk, such as higher protein and lower allergen and cholesterol concentrations. Approximately 75\% of goat milk produced in the U.S. is used in the production of cheeses, and high-quality raw milk is required to obtain products of desirable yield and quality [2].

In the United States, the legal somatic cell count (SCC) limit established by the Food and Drug Administration for dairy goat milk is 1,500,000 $\mathrm{ml}^{-1}$. However, it is common for SCC to be higher than this limit, especially near the end of lactation. Milk SCC from goats follows a linear increase throughout lactation, peaking just prior to dry-off $[3,4]$. Intramammary infections (IMI) are common in goats and have been reported to reduce milk yield and modify milk composition [5]. Coagulase-negative staphylococci (CNS) are the most frequently isolated bacteria from goat milk and typically cause subclinical disease; whereas Staphylococcus aureus is considered a major pathogen in goats and is most commonly isolated from does with clinical IMI: both CNS and S. aureus are associated with elevations in SCC, especially in late lactation [6].

Goat milk with a SCC higher than the legal limit is unsalable and must be disposed of at a financial loss to the producer. The ability to extend the amount of time a producer can ship milk by attenuating the increase in SCC that occurs late in lactation could 
prove economically valuable. Additionally, there is a well-established system of payment for milk components in the U.S. Thus, the production of milk with increased amounts of fat and protein and lower SCC may allow producers to meet the top price-quality standards for a longer period of time thereby increasing the profitability and subsequently, the sustainability of this industry.

OmniGen-AF (Phibro Animal Health Corporation, Quincy, IL, USA) is a commercially-available nutritional supplement that supports immune function in ruminant species, in part by stimulating neutrophil function and trafficking protein expression. Specific effects observed by feeding the supplement include increased neutrophil mRNA expression of L-selectin and interleukin$1 \beta$ in dexamethasone-immunosuppressed sheep [7] and altered gene expression in neutrophils isolated from periparturient dairy cows [8]. Mice fed the supplement had significantly less mammary Streptococcus uberis, Escherichia coli and S. aureus DNA concentrations following inoculation than controls in a mouse mastitis model [9]. Neutrophils from dairy heifers fed the supplement had an improved ability to phagocytose E. coli and $S$. aureus compared to controls [10,11]. Additionally, commercial dairy cows fed the nutritional supplement demonstrated improved energy corrected milk (ECM), fat corrected milk (FCM), percentage milk fat (\%MF), kilograms (kg) of milk fat and milk protein, and SCC $[12,13]$. The goal of this study was to determine the effects of dietary supplementation with OmniGen-AF on milk production, SCC, \% MF and \% MP in lactating dairy goats.

\section{Materials and Methods}

Two separate, one-year studies (replicate 1, performed in 2011 - 2012, and replicate 2, performed in 2013 - 2014) were conducted at a commercial goat dairy located in south-central Wisconsin. Both studies were approved by the Phibro Animal Health Corporation animal care and use committee.

\section{Animals and feeding}

During replicate 1, thirty-five, two-year old does were randomly assigned to one of two dietary treatments: 1) Basal diet (Control; $\mathrm{n}=18$ ), and 2) Basal diet + OmniGen-AF (OG; $\mathrm{n}=17)$. In replicate 2, forty-four, two-year old does were randomly assigned to the same dietary treatments with 22 does per treatment. Control does were group-fed a complete feed pellet twice daily (dry pellet $[0.45 \mathrm{~kg} / \mathrm{head}(\mathrm{h}) /$ day $(\mathrm{d})]$ : crude protein $(\mathrm{CP}) 14 \%$, fat $3 \%$, fiber $11.2 \%$, calcium $(\mathrm{Ca}) 1.1-1.6 \%$, copper $(\mathrm{Cu}) 37-42$ parts per million (ppm), selenium (Se) 1.0 ppm; lactating pellet (1.36 kg/h/d): CP 16\%, fat 3.4\%, fiber 8.1\%, Ca $1.1-1.6 \%$, Cu $24-28$ ppm, Se $0.8 \mathrm{ppm}$ ) and had ad libitum access to alfalfa hay and water. OG does were fed the same diet but with $1.33 \%$ OmniGen-AF incorporated into the complete feed pellet (Cargill, Incorporated, Minneapolis, MN, USA) to provide $6 \mathrm{grams}(\mathrm{g}) / \mathrm{h} / \mathrm{d}$.

In efforts to keep the two dietary treatments separate on-farm, the complete feed pellet fed to control does was stored in a bulk feed bin, whereas the pellet fed to OG does was stored in $22.7 \mathrm{~kg}$ bags. Dietary treatments were initiated upon dry-off from the first lactation (67 to 94 days before parturition) and were continued for the entire second lactation. All does (59 to $68 \mathrm{~kg}$ ) were crossbreds (Saanan, Nubian, Alpine and LaMancha) with each breed represented as equally as possible in both treatments. Does were group-housed in one straw-bedded pen for each dietary treatment. Pens were on opposite sides of a pole barn with rollup curtain sides and both pens had continual access to separate pastures. Does remained in their respective pens for the entire duration of the study (dry-off from the first lactation until dry-off from the second lactation.) Does were machine-milked twice daily in a single, twelve-stall parlor with rapid release (DeLaval, Tumba, Sweden). Milking hygiene included pre- and post-milking sanitization of teats using an iodine-based teat disinfectant. Does kidded during the months of January through March for replicate 1, and January through February for replicate 2. Does were subsequently bred during the months of August through September for replicate 1 and July through August for replicate 2. Only does that were maintained within the herd for the full duration of the study were included in the final analysis.

\section{Milk testing}

Dairy Herd Improvement Association (DHIA) milk testing was performed approximately every 28 days during lactation for a total of nine milk tests for both replicate 1 and replicate 2 . Testing was performed on milk obtained from the morning milking for both replicates. Milk production, \%MF, percentage milk protein (\%MP), FCM, ECM, SCC and linear score somatic cell count (L.S.SCC) data were collected at each test. Individual milk samples were analyzed for fat and protein content using a MilkoScan FT+ (Foss S.A., Hillerød, Denmark) and for SCC using a Fossomatic FC (Foss S.A., Hillerød, Denmark).

\section{Statistical analysis}

Results from replicate 1 and replicate 2 were combined for analysis. Data were analyzed using PROC GLM (SAS, Statistical Analysis Systems, Cary, NC, USA) with DHIA test date as a covariate and significance evaluated at the $P<0.05$ probability level and tendency for significance at $0.1>P>0.05$ probability level.

\section{Results}

The overall mean milk production, FCM, ECM, SCC, L.S.SCC, \%MF and \%MP from DHIA milk tests for OG and control does are reported in Table 1. There was no difference in milk production or L.S.SCC between treatments. However, OG does produced more milk on a fat corrected basis $(\mathrm{FCM} ; 0.25 \mathrm{~kg} ; P=0.046)$ and tended to produce more milk on an energy corrected basis $(\mathrm{ECM}$; 
$0.25 \mathrm{~kg} ; P=0.069)$ compared to controls. Overall, OG does produced milk containing $0.27 \%$ more fat $(P=0.010 ;$ Figure 1$)$ and $0.11 \%$ more protein $(P=0.049$; Figure 2$)$ than control does. OG supplementation tended to decrease SCC by $308,860 \mathrm{ml}^{-1}$ throughout the entire lactation $(P=0.089$; Figure 3$)$.

\begin{tabular}{|c|c|c|c|c|c|c|}
\hline Variable & Unit & Control Does & OG Does & & Error & P-Value \\
\hline Days in Milk (DIM) & days & 136.15 & 140.14 & \pm & 1.89 & 0.136 \\
\hline Milk Production & $\mathrm{kg}$ & 3.69 & 3.80 & \pm & 0.11 & 0.477 \\
\hline$\%$ MF & $\%$ & 3.45 & 3.72 & \pm & 0.07 & 0.010 \\
\hline$\%$ MP & $\%$ & 3.00 & 3.11 & \pm & 0.04 & 0.049 \\
\hline FCM & $\mathrm{kg}$ & 3.36 & 3.61 & \pm & 0.09 & 0.046 \\
\hline ECM & $\mathrm{kg}$ & 3.62 & 3.87 & \pm & 0.10 & 0.069 \\
\hline SCC & $\mathrm{x} 10^{3}$ cells $/ \mathrm{mL}$ & 1039.49 & 730.63 & \pm & 127.47 & 0.089 \\
\hline L.S.SCC & & 5.14 & 4.75 & \pm & 0.17 & 0.109 \\
\hline
\end{tabular}

Table 1: Overall mean ( \pm S.E.) milk production, fat corrected milk (FCM), energy corrected milk (ECM), somatic cell count (SCC), linear score somatic cell count (L.S.SCC), percentage milk fat (\%MF) and percentage milk protein (\%MP) from DHIA milk tests for control and OG does

\section{Percentage Milk Fat}

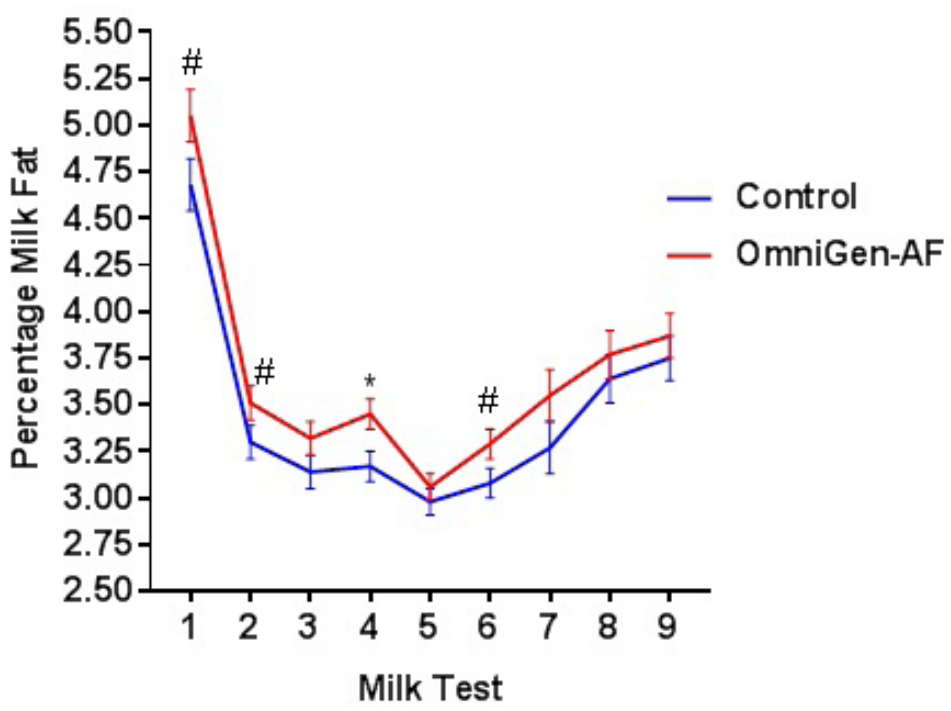

*means at milk test are significantly different $(P<0.05)$

"means at milk test tended to be different $(0.1>P>0.05)$

Figure 1: Percentage milk fat from control and OG does by DHIA milk test

\section{Percentage Milk Protein}

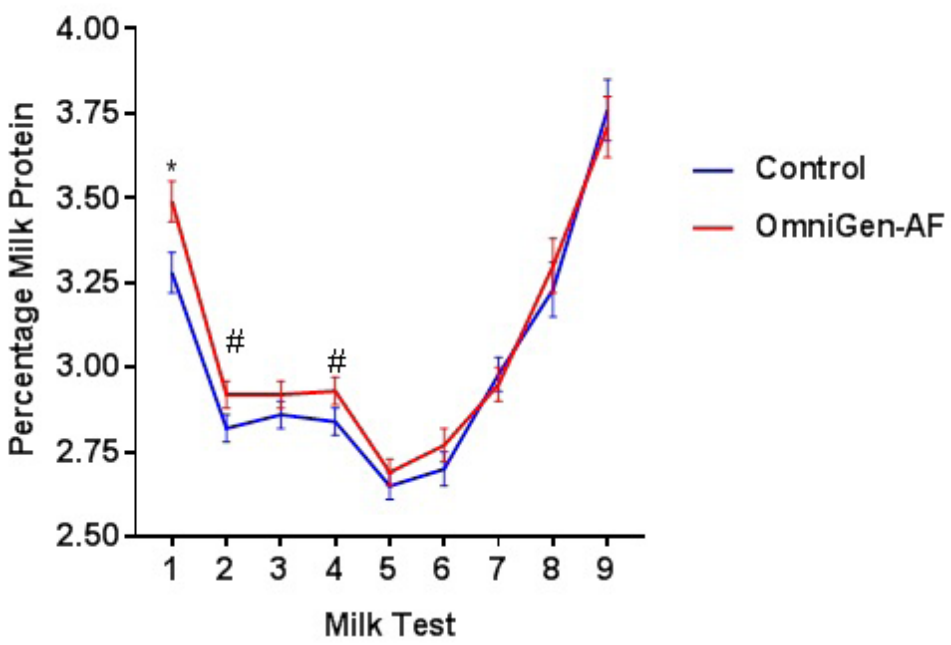

means at milk test are significantly different $(P<0.05)$

"means at milk test tended to be different $(0.1>P>0.05)$

Figure 2: Percentage milk protein from control and OG does by DHIA milk test 


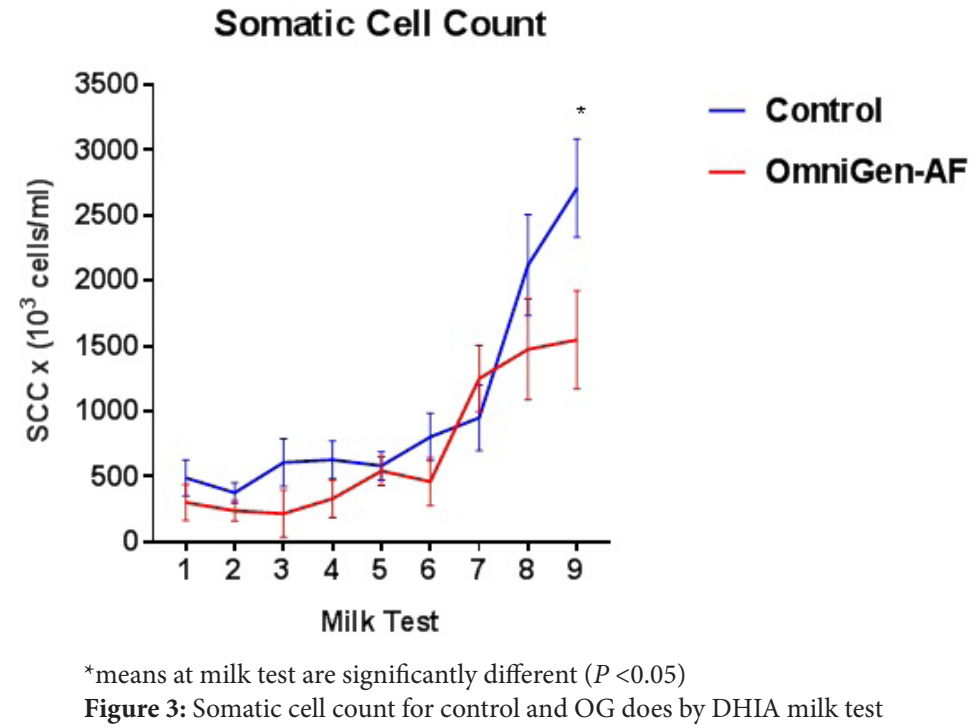

Post-hoc analyses indicated that on DHIA milk test 9 , OG does produced $0.42 \mathrm{~kg}$ more milk $(P=0.050$; Figure 4$)$ and tended to produced more milk at test $8(0.31 \mathrm{~kg} ; P=0.077)$ than controls (Figure 4$)$. OG does produced significantly more FCM on milk tests $2,3,4,8$ and 9 than controls $(P=0.034,0.031,0.043,0.037$, and 0.050 , respectively). Similarly, on milk tests $1(P=0.070)$ and $6(P=0.053)$ these comparisons tended to be different with OG does producing more FCM than controls. OG does produced more ECM on milk tests $1,2,6$ and $8(P=0.045,0.023,0.049$ and 0.046 , respectively) and tended to produce more ECM on tests 3 $(P=0.066), 4,(P=0.073)$ and $9(P=0.064)$ than controls.

Milk Production

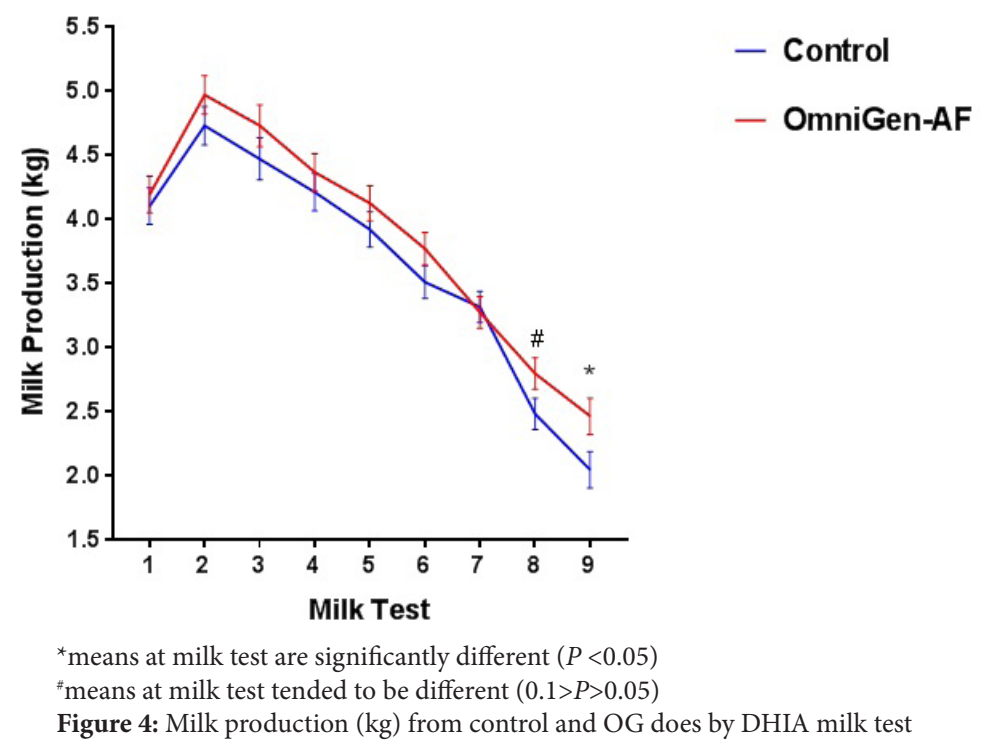

OG does produced milk containing higher \%MF on DHIA milk test $4(0.28 \% ; P=0.018)$ and tended to produce elevated $\% \mathrm{MF}$ on milk tests $1(0.37 \% ; P=0.057), 2(0.21 \% ; P=0.093)$ and $6(0.21 \% ; P=0.058)$ compared to controls (Figure 1$)$. OG does produced milk containing $0.21 \%$ more protein on milk test $1(P=0.014$; Figure 2$)$. OG supplementation tended to increase $\% \mathrm{MP}$ on tests 2 $(0.10 \% ; P=0.061)$ and $4(0.09 \% ; P=0.073)$. Differences in SCC between the two dietary treatments were more pronounced as does approached the end of lactation, where OG supplementation decreased SCC on milk test 9 by $1,163,300 \mathrm{ml}^{-1}(P=0.038$; Figure 3). Additionally, L.S.SCC was lower $(P=0.008)$ for OG does at milk test 9 compared to controls $(6.19$ and 7.23 , respectively).

\section{Discussion}

The elevated overall mean \%MF, \%MP, FCM and tendency towards lower SCC and ECM in OG does compared to controls may be explained by the fact that the nutritional supplement was consumed by does for 67 to 94 days prior to parturition and during the entire subsequent lactation. The exact mechanism by which this supplement may exert these effects in goat milk is not known. However, similar results have been reported in dairy cattle, and it is possible that the mechanism(s) responsible for these improvements are similar in goats and cattle. Heifers fed OmniGen-AF prior to parturition with continued feeding into lactation, 
had lower SCC, fewer cases of mastitis, and improved milk production compared to controls [11]. Cows consuming the nutritional supplement from dry-off through 120 DIM produced more FCM and ECM, as well as higher \%MF and kg of milk fat and milk protein [13]. Additionally, a six year study evaluating health and production records collected from prior to and during the feeding of OmniGen-AF demonstrated a reduction in SCC and fewer mastitis cases per month [12]. DHIA testing was not performed during the does' first lactation, so it is possible that random assignment of does with higher milk production, \%MF and \%MP into the OG treatment occurred, however, this is unlikely considering data from two separate replicates support these biological effects.

The dairy goat lactation cycle is characterized by higher SCC compared to the more commonly investigated cow. The higher SCC presents issues for dairy goat production systems and provides a unique model to investigate the use of management approaches designed to lower SCC. Supplementation with OmniGen-AF in both replicates resulted in a tendency for lower overall mean SCC between OG does and controls, with differences in SCC between the two dietary treatments being more pronounced as does approached the end of lactation.

It is common in dairy goats for milk SCC to progressively increase throughout lactation, peaking just prior to dry-off [3,4]. The SCC of does included in this study followed this pattern, although the rise in SCC was attenuated in OG does. Multiple studies have shown that the SCC of milk is directly correlated to infection status $[6,14,15]$. Several authors have also stated that SCC values above the legal limit are commonly observed in nonmastitic goat milk late in lactation, with neutrophils being the predominant white blood cell type despite the absence of infection [3-5] and no histologic evidence of tissue damage [16]. A concentration effect due to a reduction in milk yield at the end of lactation can only in part explain this phenomenon. Manlongat et al. [17] suggests that a yet to be named physiologic chemotactic factor(s) in the mammary gland is responsible for the increase in SCC and neutrophil infiltration in goat milk in the absence of mastitis during late lactation. Alternatively, Leitner et al. [18] describes that the end of lactation in goats is characterized by a sharp increase in plasmin activity which results in accelerated casein breakdown and the production of proinflammatory components. Thus, the increase in plasmin activity is associated with a sharp increase in SCC, which results in a sterile inflammatory response. It's possible that one of these mechanisms, a combination of both mechanisms, or a yet to be determined alternative mechanism is responsible for this phenomenon in goat milk at the end of lactation. It's also possible that the consumption of OmniGen-AF augments or modulates these physiologic immune-related mechanisms resulting in lower SCC. Further research is warranted to elucidate to exact mechanism involved.

Only two year old does were selected for use in both replicates. This decision was made in efforts to reduce variability as lactation number can influence several of the measured endpoints. For example, higher parity does have been reported to have higher SCC [19], greater milk production [20,21] and elevated milk protein content [21] than lower parity does, whereas lower parity does have been shown to have greater milk fat content [21]. By including the same age does in each treatment of both replicates, the impact of lactation number is eliminated. Both replicates were conducted on the same commercial goat dairy (approximately 185 milking does) two years apart (replicate 1 in 2011 - 2012 and replicate 2 in 2013 - 2014) and all two-year old does housed on the dairy at the initiation of each replicate were included, thereby limiting the number of does per replicate. This number equated to 35 does for replicate 1 and 44 does for replicate 2. Two replicate studies were conducted in efforts to increase the number of does exposed to each treatment and to determine repeatability of the results.

Pooling the data from replicates 1 and 2 provided the most statistically useful analysis, however, the conditions and data from each replicate were considered for further interpretation. For example, due to management decisions made by the owners of the dairy, does in the control group in replicate 2 were exposed to a buck approximately three weeks earlier than does in the OG group in this replicate. This timing resulted in the majority of OG does exhibiting estrus at the time of DHIA milk test 7, when the majority of control does were already out of estrus. This may be a factor as to why the mean SCC of OG does was numerically higher than controls (1,250,900 $\mathrm{ml}^{-1}$ and 950,000 ml-1, respectively) at this time point. An increase in SCC coincident with estrus has been reported previously in goats and was found to be independent of a decline in milk volume [22]. The mechanism responsible for the phenomenon remains unexplained.

It has been demonstrated that the beneficial effects of this nutritional supplement are more pronounced during induced or naturaloccurring stressors such as administration of dexamethasone and parturition. For example, Wang et al. [7] determined that OmniGen-AF countered the dexamethasone-dependent down-regulation of markers of innate immune function (L-selectin and IL-1 $\beta$ ) in sheep, while Ortiz-Marty et al. [23] established that the supplement prevented L-selectin suppression in wild-type mice injected with dexamethasone. Furthermore, dairy cows fed the nutritional supplement prior to parturition demonstrated differential expression of eighteen neutrophil genes on the day of calving [8]. OmniGen-AF supplementation for 60 days prepartum reportedly ameliorated the immunosuppression typically observed in dairy cows around the time of parturition [10]. Possible mechanisms by which the nutritional supplement has these effects include induction of the cell surface proteins L-selectin and IL-8R by neutrophils which improve the ability of this cell type to respond to immunological challenges and to phagocytose pathogens by promoting diapedesis and migration to infection sites $[10,11,24]$. Furthermore, lactating dairy cows fed OmniGen-AF produced less cortisol than controls during heat stress [25] and in response to corticotropin releasing hormone and vasopressin or adrenocorticotropic hormone challenge during both heat stress and thermoneutral conditions [26]. Therefore, the more pronounced beneficial effects of this nutritional supplement during times of stress could also be explained by the reduction in circulating cortisol. 
Although no planned stress was included in the studies described herein, replicate 2 does were exposed to unusual regionally cold weather during the late dry period, at the time of parturition and during early lactation. Cold stress can negatively impact milk production and increase circulating plasma corticosteroid concentrations in goats [27,28]. Thus, the increases in milk production, FCM and ECM may be due to the nutritional supplement's support of the goats' immune systems and animal health manifested as higher milk production during replicate 2.

OmniGen-AF supplementation results in an increase in certain measurements associated with the innate immune system and this response takes $30-60$ days to occur in cattle $[8,10,24]$. The period of time associated with parturition commonly referred to as transition in dairy cattle is associated with an increase in cortisol production and a subsequent decrease in the effectiveness of the innate immune system [29]. Indeed, the expression of proteins associated with suppressed immune system function during the period of time of parturition [30] have been reported to be supported by OmniGen-AF supplementation [7,10,24]. Thus, it is important to maintain a functional immune system during the time around parturition to support animal health and the complexity of this support and immune system response may require feeding nutritional supplements for extended periods to gain the full benefit. Therefore, OmniGen-AF was included in the diets of does in both replicates starting at dry-off from the first lactation and continued for the entire second lactation.

It is expected that different environmental, nutritional and genetic factors may play a role in differential responses of animals to nutritional supplements. However, health benefits observed with this nutritional supplement indicate a consistent response associated with support of immune function. Further investigation of the mode of action may provide more insight into the relationship between stress, immune system function and production endpoints in ruminants.

\section{Conclusion}

In this study, dairy goats fed OmniGen-AF for 67 to 94 days prior to parturition and for the entire subsequent lactation had significantly elevated \%MF, \%MP and FCM, tended to have higher ECM and tended to have lower SCC than controls. These data combined with studies performed in bovine suggest that this nutritional supplement could modulate mammary gland health in ruminants.

\section{Acknowledgement}

All of the authors except Dr. Lane Ely are employees of Phibro Animal Health Corporation (Quincy, IL), which manufactures, sells and distributes OmniGen-AF nationally and internationally.

\section{References}

1. USDA-NASS (2016) Sheep and Goats In: United States Department of Agriculture, National Agricultural Statistics Service, Washington, DC, USA.

2. USDA-NASS (2008) Goat milk processor survey In: United States Department of Agriculture, National Agricultural Statistics Service, Madison, WI.

3. Rota AM, Gonzalo C, Rodriguez PL, Rojas AI, Martin L, et al. (1993) Effects of stage of lactation and parity on somatic cell counts in milk of Verata goats and algebraic models of their lactation curves. Small Rumin Res 12: 211-19.

4. Paape MJ, Wiggans GR, Bannerman DD, Thomas DL, Sanders AH, et al. (2007) Monitoring goat and sheep milk somatic cell counts. Small Rumin Res 68: 114-25.

5. Barron-Bravo OG, Gutierrez-Chavez AJ, Angel-Sahagun CA, Montaldo HH, Shepard L, et al. (2013) Losses in yield, fat and protein contents according to different levels of somatic cell count in dairy goats. Small Rumin Res 113: 421-31.

6. Bergonier D, de Crémoux R, Rupp R, Lagriffoul G, Berthelot X (2003) Mastitis of dairy small ruminants. Vet Res 34: 689-716.

7. Wang YQ, Puntenney SB, Burton JL, Forsberg NE (2007) Ability of a commercial feed additive to modulate expression of innate immunity in sheep immunosuppressed with dexamethasone. Animal 1: 945-51.

8. Wang YQ, Puntenney SB, Burton JL, Forsberg NE (2009) Use of gene profiling to evaluate the effects of a feed additive on immune function in periparturient dairy cattle. J Anim Physiol Anim Nutr 93: 66-75.

9. Rowson AD, Wang YQ, Aalseth E, Forsberg NE, Puntenney SB (2011) Effects of an immunomodulatory feed additive on the development of mastitis in a mouse infection model using four bovine-origin isolates. Animal 5: 220-9.

10. Nace EL, Nickerson SC, Kautz FM, Breidling S, Wochele D, et al. (2014) Modulation of innate immune function and phenotype in bred dairy heifers during the periparturient period induced by feeding an immunostimulant for 60 days prior to delivery. Vet Immunol Immunopathol 161: 240-50.

11. Eubanks VJ, Hurley DJ, Ely LO, Kautz FM, Nickerson SC, et al. (2012) Pre- and postpartum immunomodulatory effects of a dietary supplement on the immune system of dairy heifers. J Dairy Sci 95: 222.

12. Bewley O, Boyle T, Brady M, Brubaker K, Chapman J, et al. (2014) A six year study evaluating health, milk and milk quality in 427 dairy herds fed OmniGen-AF to dry and lactating cows. J Dairy Sci 97: 718.

13. Holland AE, Rivera FE, Chapman JD, Ely LO (2015) Health, milk, milk components, milk quality and reproduction evaluated in Holstein cows fed OmniGenAF from dry-off through 120 days in milk. J Dairy Sci 98: 452.

14. Kalogridou-Vassiliadou D, Manolkidis K, Tsigoida A (1992) Somatic cell counts in relation to infection status of the goat udder. J Dairy Res 59: 21-8.

15. Droke EA, Paape MJ, Di Carlo AL (1993) Prevalence of high somatic cell counts in bulk tank goat milk. J Dairy Sci 76: 1035-9.

16. Zeng SS, Escobar EN (1994) Factors affecting somatic cell count of goat milk throughout lactation: parity and milk production. In: Somatic cells and milk of small ruminants: proceedings of international symposium. Bella, Italy. International Dairy Federation, Brussels, Belgium.

17. Manlongat N, Yang TJ, Hinckley LS, Bendel RB, Krider HM (1998) Physiologic-chemoattractant-induced migration of polymorphonuclear leukocytes in milk Clin Diagn Lab Immun 5: 375-81. 
18. Leitner G, Merin U, Silanikove N (2011) Effects of glandular bacterial infection and stage of lactation on milk clotting parameters: comparison among cows, goats and sheep. Int Dairy J 21: 279-85.

19. Contreras A, Paape MJ, Miller RH (1999) Prevalence of subclinical intramammary infection caused by Staphylococcus epidermis in a commercial dairy goat herd. Small Rumin Res 31: 203-8.

20. Anwar MM, Ramadan TA, Taha TA (2012) Serum metabolites, milk yield, and physiological responses during the first week after kidding in Anglo-Nubian, Angora, Baladi, and Damascus goats under subtropical conditions. J Anim Sci 90: 4795-806.

21. Macciotta NP, Fresi P, Usai G, Cappio-Borlino A (2005) Lactation curves of Sarda breed goats estimated with test day models. J Dairy Res 74: 470-5.

22. McDougall S, Voermans M (2002) Influence of estrus on somatic cell count in dairy goats. J Dairy Sci 85: 378-83.

23. Ortiz-Marty RJ, Forsberg NE, Chapman JD, Mullarky IK (2012) OmniGen-AF restores GR-1, 1-selectin, and RANTES expression by immunosuppressed murine PMN challenged with lipopolysaccharide in a MyD88-dependent manner. J Dairy Sci 96: 397.

24. Ryman VE, Nickerson SC, Kautz FM, Hurley DJ, Ely LO, et al. (2013) Effect of dietary supplementation on the antimicrobial activity of blood leukocytes isolated from Holstein heifers. Res Vet Sci 95: 969-74.

25. Hall LW, Villar FA, Allen JD, Chapman JD, Long NM, et al. (2014) The effects of OmniGen-AF on serum metabolites, calcium concentrations and hormones of the adrenal axis during heat stress in lactating Holstein cows. J Dairy Sci 97: 905.

26. McBride ML, Burdick-Sanchez NC, Carroll JA, Broadway PR, Ortiz XO, et al. (2016) OmniGen-AF reduces basal plasma cortisol as well as cortisol release to adrenocorticotropic hormone or corticotropin releasing hormone and vasopressin in lactating dairy cows under thermoneutral or acute heat stress. J Dairy Sci (In Press).

27. Thompson GE, Thomson EM (1972) Effect of cold exposure on mammary circulation, oxygen consumption and milk secretion in the goat. J Physiol 272: 18796.

28. Faulkner A, Thomson EM, Bassett JM, Thomson GE (1980) Cold exposure and mammary glucose metabolism in the lactating goat. Br J Nutr 43: 163-70.

29. Weber PSD, Madsen SA, Smith GW, Ireland JJ, Burton JL (2001) Pre-translational regulation of neutrophil L-selectin in glucocorticoid-challenged cattle. Vet Immunol Immunopathol 83: 213-40.

30. Burton JL, Erskine RJ (2003) Immunity and mastitis. Some new ideas for an old disease. Vet Clin Food Anim 19: 1-45.

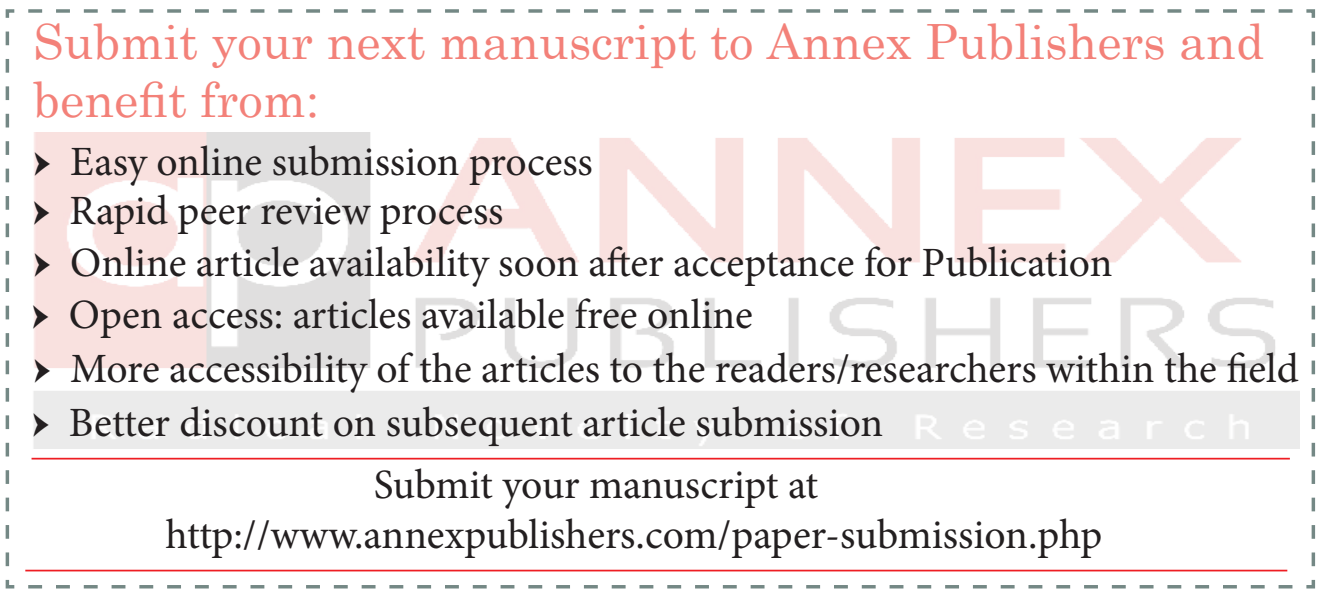

